\title{
The Effect of Chinese Herb on Tumor Angiogenesis by Inhibiting Vessel Endothelial Cells
}

\author{
Jian Jin, Li-Ying Qiu, Hui Hua and Lei Feng \\ The School of Medicine and Pharmaceutics, Jiang Nan University,
}

China

\section{Introduction}

Currently, anti-angiogenesis drugs are the popular treatment for cancer, which, however, are not without serious drawbacks. Virtually all such drugs are recombinant peptides/proteins or therapeutic antibodies and thus can only be administered via intravenous injection. In addition, these drugs tend to have low stability and short half life in vivo, which demands long treatment at high doses, which in turn renders the therapy expansive and could lead to high occurrences of side effects. Furthermore, these drugs usually target only one, out of many, step or pathway of angiogenesis and are not very effective. Even Avastin, the top-selling anti-tumor angiogenesis drug on the market, can only extend patients' life span by $4 \sim 6$ months without a cure. Therefore, it is necessary to develop efficacious, affordable, and orally available angiogenesis-inhibiting drugs.

We report here the high-throughput screening (HTS) of over 500 Chinese medicinal herbs and plants in human vessel endothelial cell (HMEC-1) proliferation inhibition assay, which leads to the discovery of several candidate drugs with neovascularization inhibition property. Study on seropharmacology of several medicinal herbs/plants including albizia bark and Semen Vaccariae demonstrated their specific inhibition on HMEC-1 growth, suggesting their potential use as oral drugs for neovascularization inhibition. (seropharmacology as a new screen method to study Chinese medical effects in vitro, which cultive cells by medium containing a serum from animals of oral adminstrated a medicine. It is to be proved that the medicine has the effect after oral the medicine. And it paves a highway for investigation of traditional Chinese medicine. The standardized methodology of seropharmacology was initiaed to help to the exensive application of this technology.) Our study aims to investigate the efficacy and mechanism of such inhibition of albizia bark extracts, its effective moiety and effective monomer in multiple angiogenesis models.

\section{Reagents and methods}

\subsection{Reagents}

MEM culture media was obtained from Gibco (City, Country). Sulforhodamine B (SRB) and bFGF were obtained from Sigma (St. Louis, MO, USA). FCS, trypsin, L-glutamine were purchased from Huamei Biological Company (Bejing, China). Anti- CD31 monoclonal antibody and immunohistochemisty kit were purchased from Zhongshan Jinqiao 
Biotechnology Technical Service Co. Ltd. (Beijing, China). DAPI kit, TUNEL apoptosis kit, JC-1, Caspase-3, 9 spectrophotometry kit, mitotic cycle kit, and Annexin V-FITC apoptosis kit were obtained from Kaiji Biological Company (Nanjing, China). Cortex albiziae and licorice root were purchased from Shanhe Pharmaceutical Co. Ltd (Wuxi, China).

\subsection{Cell lines}

CPAE was kindly provided by Dr. J. Badet (Créteil University, Paris, France). Human microvascular endothelial cell line (HMEC-1) and human lung embryonic fibrocyte (MRC5) were generous gifts from Dr. He Lu (INSERM U553, National Institute for Health and Medicine Research, France). $\mathrm{B}_{16}$ melanoma, breast cancer cell (MCF-7) and Hepatocellular carcinoma $\left(\mathrm{HepG}_{2}\right)$ were purchased from Institute, Chinese Academy of Sciences (Beijing, China). Cells are routinely maintained in MCDB complete culture medium in a $37^{\circ} \mathrm{C}$ incubator with a humidified atmosphere containing $5 \% \mathrm{CO}_{2}$.

\subsection{Animals}

Swiss nude mice and BALB/c mice were purchased from Shanghai Laboratory Animal Center, Chinese Academy of Sciences (Shanghai, China). Nude and C57bl/ 6 mice were used for human C51 colon cancer and mouse Lewis lung carcinoma ,respecctively,which were obtained from Tumor Research Center, Chinese Academy of Sciences (Beijing, China). Fertilized eggs were purchased from Mashan Poultry Center (Wuxi, China).

\subsection{Herbal extracts}

Albizia bark and licorice root were soaked in 5-volume of cold water for $2 \mathrm{~h}$, boiled for 30 $\mathrm{min}$, and strained. The remaining herbal material was returned to boil for $30 \mathrm{~min}$ in 3volume of water and strained. Both filtrates were combined and condensed in a waterbath to a concentrate of $1 \mathrm{~g}$ of starting herbal material per $\mathrm{mL}$. It totally get finished for 2 or 3 days

\subsection{Purification of active monomer}

Albizia bark extracts was loaded onto a D-101 resin column. About 70\% of the ethanol elutes containing active ingredient were collected, as monitored by an in vitro activity assay. Further purification was carried out using standard silica gel column chromatography with a solvent system of chloroform-methanol-water for elution, antiphase styrene column chromatography, and antiphase C18 column chromatography to obtain the active ingredient at a purity of more than $90 \%$. It is named julibroside $J_{8}$, its constituents identified as $3-0-[\beta-D-$ xylopyranosyl-( $1 \rightarrow 2)-\beta$-D-fucopyranosyl-( $1 \rightarrow 6)-\beta$-D-gluCopyranosyl]-21-o- $\{(6 \mathrm{~s})-2$-trans-2hydroxymethyl-6-methyl-6-o-[4-o-((6R)-2-trans-2,6-dimethyl-6-o- $\beta$-D-quinovopyranosyl)2,7-octadienoyl)- $\beta$-D-quinovopyranosyl]-2,7-octadienoyl\}-acacicacid-28-o- $\beta$-D-

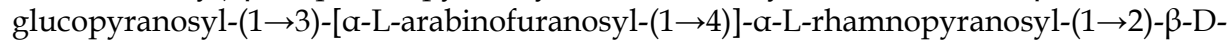
glucopyranosyl ester (structure shown in Fig. 1).

\subsection{HMEC-1 cell proliferation inhibition assay}

HMEC-1 cells were seeded in 96-well plates at $7000 \sim 8000$ cells per well and cultured for $24 \mathrm{~h}$ and the volume of cell suspension in each plate is $150 \mu \mathrm{L}$. Following the addition of herbal extract with $150 \mu \mathrm{L}$ in each plate, cells were cultured for another $48 \mathrm{~h}$. Wells containing culture medium alone and those with untreated cells were served as blank and negative control, respectively. The experiment was carried out in quadruplicate and analyzed by SRB method. 


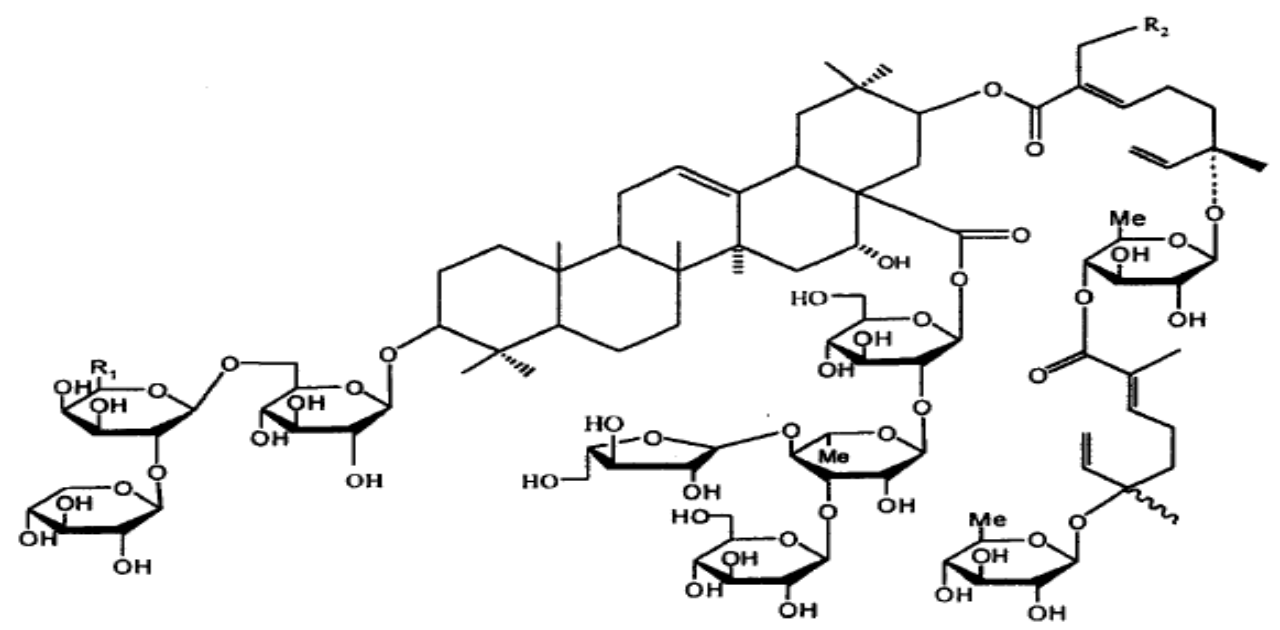

Fig. 1. Chemical structure of compound j8.

SRB assay was used to get the result of drug sensitivity assay of carcinoma. The effect of compound on proliferation inhibition was calculated according to the formula listed below:

$$
\text { percentage inhibition }(\%)=\frac{(\text { negative control signal }- \text { test well signal })}{(\text { negative control signal }- \text { blank well signal })} \times 100
$$

\subsection{Chick chorioallantoic membrane (CAM) assay}

Fresh fertilized eggs ( $50 \pm 5 \mathrm{~g}$ each) with intact shell were selected for the experiment. They were soaked in $0.1 \%$ benzalkonium bromide for $3 \mathrm{~min}$, and then placed in an incubator maintained at $37.8 \pm 0.50 \mathrm{C}$ with a relative humidity of $65 \% \sim 70 \%$. The eggs were turned daily once in the morning and once in the evening and sorted into groups of 10, based on their embryonic age. Three treatment groups were dosed with albizia bark extract at 100, 500 and $1000 \mu \mathrm{g} / \mathrm{mL}$, whereas the negative control group were given normal saline only. Compounds were spotted onto sterile filter paper discs $(4 \mathrm{~mm} \times 4 \mathrm{~mm})$ and air dried. The discs were subsequently placed onto the CAM between two vitelline veins through a window made in the eggshell and the window was sealed with sterile clear tape. Following an additional incubation for 2 3 days, seals were removed to expose the CAM; the blood vessels surround the disc (within a radius of $8 \mathrm{~mm}$ ) was counted and sorted into 3 categories based on their size; their vascular branching pattern and density were also noted.

\subsection{Matrigel plug assay ${ }^{[1-2]}$}

Eight-week-old female Swiss nude mice (18-22 g) were randomized into four groups ( $\mathrm{N}=5$ per group) injected with $0.3 \mathrm{ml}$ Martrigel subcutaneously at ventral lateral side; an oral dosing regimen was followed and started on the same day. One group received albizia bark extract at $8 \mathrm{mg} / \mathrm{kg}$ per day, while the other were given normal saline and served as control. Mice were sacrificed after seven consecutive days of daily dosing; Matrigel plugs were removed, fixed in ethanol, and embedded in paraffin. Immunohistochemistry was 
performed on the sections for PECAM-1, a vessel endothelial cell marker, and blood vessels were counted on BX-40 optical microscope (Olympus, Japan).

\subsection{Pharmacodynamic analysis of Albizia bark extract in $\mathbf{C}_{51}$ nude mice model of colon cancer}

Fifteen nude mice (about $20 \mathrm{~g}$ ) were randomly assigned to three groups ( $\mathrm{N}=5$ per group) and inoculated subcutaneously with $5 \times 10^{7}$ of $\mathrm{C} 51$ colon cancer cells under right armpit. Daily oral dosing started 10 days after inoculation, when the size of tumor reached $8-10 \mathrm{~mm}^{3}$, and lasted for 4 weeks. The blank group received normal saline, control group licorice extract (8 $\mathrm{mg} / \mathrm{kg})$, and treatment group albizia bark extract $(8 \mathrm{mg} / \mathrm{kg})$. Mice were sacrificed by cervical dislocation on Day 28. A portion of tumor tissue was fixed in $4 \%$ formaldehyde, embedded in paraffin and sectioned, sectioned into a thickness of $5 \mu \mathrm{m}$, and then stained with. Immunohistochemistry was performed on the sections for PECAM-1, blood vessels counted on BX-40 optical microscope (Olympus, Japan) with an overall magnification of 200x, and microvascular density (MVD) determined as previously described. It has been done for two weeks.

\subsection{Pharmacodynamic analysis of albizia bark extract in nude mice model of lung cancer metastasis}

Seven-week-old female C57BL/ 6 mice (18-20g) were randomized into three groups ( $\mathrm{N}=8 \sim 10$ per group) and inoculated with $0.2 \mathrm{ml}$ of Lewis lung cancer (LLC) cell suspension (5x106/L) by ventral subcutaneous injection. Seven days later, treatment group were administered albizia bark ingredients or licorice by gavage daily, whereas control group received normal saline. Mice were sacrificed after 15 days. Lungs were fixed, in $4 \%$ formaldehyde and embedded in paraffin and sectioned for H\&E staining. Three nonconsecutive sections from each sample were analyzed to determine the mean numbleof lung metastases.

\subsection{Cell migration assay using scratch wound healing ${ }^{[3]}$}

HMEC-1 cells were seeded in 24-well plate at $8 \times 10^{4}$ cells per well, respectively, and incubated for $24 \mathrm{~h}$ to allow attachment. A scratch of $1 \mathrm{~mm}$ in width was introduced at the center of each well by drawing a plastic pipette tip across the surface of cell monolayer and detached cells were washed off with PBS. Media containing drugs at various concentrations were then added to each well and cells were photographed immediately with a 100x magnification and the resulting image was defined as the migration map at $0 \mathrm{~h}$. Subsequently, cells were photographed in the same visual field at $6 \mathrm{~h}, 12 \mathrm{~h}, 24 \mathrm{~h}$, and $48 \mathrm{~h}$ respectively. Images obtained were processed with software IPWin60C and the distance between two opposing wound margins was measured. Cell mobility was calculated based on 6 measurements taken at randomly selected sites per image.

\subsection{Tube formation assay ${ }^{[4]}$}

Matrigel was thawed at $4^{\circ} \mathrm{C} \mathrm{O} / \mathrm{N}$ and added to 24 -well plates that had been pre-chilled on ice at $150 \mu \mathrm{l}$ per well. The plates were placed in a $370 \mathrm{C} / 5 \% \mathrm{CO}_{2}$ incubator for $30 \mathrm{~min}$. 3B11 cell suspension $\left(4 \times 10^{5}\right.$ cells $\left./ \mathrm{ml}\right)$ was mixed with equal volume of cell culture media containing different concentrations of drugs and a total volume of $200 \mu \mathrm{l}$ was plated in each well of a Matrigel plate. Cells were incubated in a $370 \mathrm{C} / 5 \% \mathrm{CO}_{2}$ incubator for $12 \mathrm{~h}$ and photographed periodically. 


\subsection{H\&E staining}

HMEC-1 single cell suspension was add to a 6-well plate at $10^{4}$ or $10^{5}$ per well and cultured on glass coverslips for $24 \mathrm{~h}$, followed by further culture of $48 \mathrm{~h}$ in the presence of drugs at various concentration. After decanting culture media, coverslips were washed three times with PBS, fixed with formalin for $10 \mathrm{~min}$, and stained with hematoxylin and eosin. 10 Kunming mice (20-22g) were administered J8 for 10 days, mice were sacrificed. Lungs liver, and kidney were fixed, embedded in paraffin and sectioned for H\&E staining. The change in cell morphology was observed under the microscope.

\subsection{DAPI staining}

HMEC-1 cells in logarithmic phase were plated in tissue culture dish and cultured on glass coverslip for $24 \mathrm{~h}$ to allow adhesion. Julibroside $\mathrm{J}_{8}$ was added to a final concentration of $0.5,1.0$, and $2.5 \mu \mathrm{g} / \mathrm{mL}$, while the control received no compound, and cells were cultured for another 24h. Coverslips were washed in PBS followed by DAPI staining buffer, stained in DAPI working solution at $37^{\circ} \mathrm{C}$ for $15 \mathrm{~min}$, rinsed in methanol and mounted in glycerol. The nuclear staining was examined on a fluorescence microscope with an oil-immersion lens.

\subsection{TUNEL assay}

HMEC-1 cells in logarithmic phase were plated in tissue culture dish and cultured on glass coverslips for $24 \mathrm{~h}$. Julibroside $J_{8}$ was added to a final concentration of $0.5,1.0$, and $2.5 \mu \mathrm{g} /$ $\mathrm{mL}$, while the control received no compound, and cells were cultured for another 24h. Coverslips were fixed in freshly prepared $4 \%$ paraformaldehyde (PFA) at RT for $15 \mathrm{~min} \sim 1 \mathrm{~h}$. blocked in $3 \% \mathrm{H}_{2} \mathrm{O}_{2} / \mathrm{MeOH}$ at RT for $10 \mathrm{~min}$, and permeabilized in freshly prepared $0.1 \%$ Triton X-100 / 0.1\% sodium citrate on ice for 2 minutes. Washed samples were incubated with $50 \mu \mathrm{L}$ fresh TdT reaction mix in the dark for 60 minutes at $370 \mathrm{C}$ in a humidified chamber. Negative controls were incubated with TdT reaction mix without TdT enzyme. Samples were washed in PBS three times and incubated with $50 \mu \mathrm{L}$ Streptavidin-HRP solution in the dark for 30 minutes at $37^{\circ} \mathrm{C}$ in a humidified chamber. Fresh DAB solution was applied to washed coverslips for 10 minutes at RT, which were subsequently rinsed, counterstained with hematoxylin and mounted.

\subsection{Detection of cell death and apoptosis by flow cytometry (FCM)}

HMEC-1 cells in logarithmic growth phase were inoculated into cell culture flask at $5 \times 10^{5}$ cell $/ \mathrm{ml}$ in MCDB complete medium for $24 \mathrm{~h}$. Julibroside $J_{8}$ was added to a final concentration of $0.5 \sim 2.5 \mu \mathrm{g} / \mathrm{ml}$ and cells were cultured for another $48 \mathrm{~h}$. The blank control received no compound. Cells were trypsinized, washed three times with PBS, and resuspended in $200 \mu \mathrm{L}$ binding buffer. $10 \mu \mathrm{L}$ Annexin V-FITC was added into the cell suspension and incubated at RT protected from light for $30 \mathrm{~min}$, followed by the addition of $5 \mu \mathrm{L}$ propidium iodide (PI) and continued incubation for another $5 \mathrm{~min}$. With the addition of $400 \mu \mathrm{L}$ Binding buffer working solution, cells were ready for FCM.

\subsection{Analysis of cell cycle and DNA content by FCM}

HMEC-1 cells in logarithmic growth phase were inoculated into cell culture flask at $5 \times 10^{5}$ cell $/ \mathrm{ml}$ in MCDB complete medium for $24 \mathrm{~h}$. Julibroside $J_{8}$ was added to a final concentration 
of $0.5 \sim 2.5 \mu \mathrm{g} / \mathrm{ml}$ and cells were further cultured for $48 \mathrm{~h}$. The blank control received no compound. Cells were trypsinized, washed twice with PBS, and resuspended in $500 \mu \mathrm{L}$ PBS. While gently mixing, $1.5 \mathrm{~mL}$ of cold $70 \% \mathrm{EtOH}$ in PBS (pre-chilled at $-20{ }^{\circ} \mathrm{C}$ ) were added into cell suspension dropwise and the mixture was placed in the refrigerator for at least 24h. Prior to FCM analysis, cells were washed twice with PBS, resuspended in $1 \mathrm{ml}$ PI staining solution (PI at $100 \mu \mathrm{g} / \mathrm{ml}$ in PBS with $100 \mu \mathrm{g} / \mathrm{ml}$ DNase-free RNase A) and incubated at $4^{\circ} \mathrm{C}$ for 30 min protected from light. The stained cells were washed in PBS, then resuspended in up to $1 \mathrm{ml}$ of PBS, and strained through a 200 mesh screen. The cells were put through FCM; data from 5,000-10,000 cells per sample were analyzed using software Cellfit (BD Biosciences, USA).

\subsection{Analysis of mitochondrial membrane potential by FCM}

HMEC-1 cells in logarithmic growth phase were inoculated into cell culture flask at $5 \times 10^{5}$ cell $/ \mathrm{ml}$ in MCDB complete medium for $24 \mathrm{~h}$. Julibroside $\mathrm{J}_{8}$ was added to a final concentration of $0.5 \sim 2.5 \mu \mathrm{g} / \mathrm{ml}$ and cells were cultured for another $24 \mathrm{~h}$. The blank control received no compound. Cells were trypsinized and washed twice with PBS. No more than $10^{6}$ cells were collected and resuspended in 500 ul lipophilic cation 5,5',6,6'-tetrachloro-1,1',3,3'tetraethylbenzimidazolcarbocyanine iodide (JC-1) staining solution. JC-1 is more advantageous over rhodamines and other carbocyanines, capable of entering selectively into mitochondria, since it changes reversibly its color from green to orange as membrane potentials increase (over values of about $80-100 \mathrm{mV}$ ). This property is due to the reversible formation of JC-1 aggregates upon membrane polarization that causes shifts in emitted light from $530 \mathrm{~nm}$ (i.e., emission of JC-1 monomeric form) to $590 \mathrm{~nm}$ (i.e., emission of J-aggregate) when excited at $490 \mathrm{~nm}$; the color of the dye changes reversibly from green to greenish orange as the mitochondrial membrane becomes more polarized. Both colors can be detected using the filters commonly mounted in all flow cytometers, so that green emission can be analyzed in fluorescence channel 1 (FL1) and greenish orange emission in channel 2 (FL2), subsequently incubated in a CO2 incubator at $37^{\circ} \mathrm{C}$ for $15 \sim 20 \mathrm{~min}$. Cells were then pelleted at RT (2000 rpm, $5 \mathrm{~min}$ ) and washed twice with incubation buffer. Finally, cells were resuspended in $500 \mathrm{ul}$ of incubation buffer and ready for FCM.

\subsection{Determination of Caspase-3, 9 content in endothelial cells by spectrophotometer}

HMEC-1 cells of logarithmic growth phase were seeded in cell culture flasks at $5 \times 10^{5}$ cell $/ \mathrm{mL}$. After $24 \mathrm{~h}$, julibroside $\mathrm{J}_{8}$ was added to a final concentration of $1.5 \mu \mathrm{g} / \mathrm{mL}$. Cells were harvested at 4, 8 and 12 hours after drug treatment and $5 \times 10^{6}$ cells were collected at each time point. Cells were washed twice with PBS. After the 2 nd wash, cells were centrifuged at $2000 \mathrm{rpm}$ for $5 \mathrm{~min}$ and the supernatant was discarded. $150 \mu \mathrm{L}$ of ice-cold Lysis Buffer was used to resuspend the cell pellet; the resulting cell extraction was placed on ice for $20 \sim 60$ min, with $3 \sim 4$ short vortexes (10 sec each time) in between. The extraction was centrifuged at $4^{\circ} \mathrm{C}(10,000 \mathrm{rpm}, 1 \mathrm{~min})$ and the supernatant, or the lysate, was carefully transferred to a fresh eppendorf (EP )tube and stored on ice. $50 \mu \mathrm{L}$ of cell lysate was used for caspase- 3 and caspase- 9 enzyme activity measurement with caspase- 3 and caspase- 9 activity assay kits by spectrophotometry. Meanwhile, the protein concentration was determined by Bradford assay to normalize caspase activity by $\mathrm{mg}$ of protein. All assays were performed according to manufactures' instructions. 


\section{Results}

\subsection{Albizia bark extracts on neovascularization}

\subsubsection{Albizia bark extracts inhibit neovascularization in CAM assay}

CAM assay is one of several classical in vivo models for studying angiogenesis. We found here that CAM treated with normal saline showed prominent angiogenesis. A large number of vessels radiated from underneath the control disc and were highly branched, which led to abundant capillaries that are responsible for the vibrant color of the CAM (Fig. 2, left panels). However, the number of vessels radiating from disc treated with albizia at 500 $\mathrm{ug} / \mathrm{mL}$ was greatly reduced, and the vessels were sparse, disorganized, with a light yellow appearance (Fig. 2, right panels). The effect was dose-dependent and the phenotype was more pronounced with increased albiziae at $1000 \mathrm{ug} / \mathrm{mL}$ (Table 1), suggesting that albizia extract is an inhibitor of neovascularization.
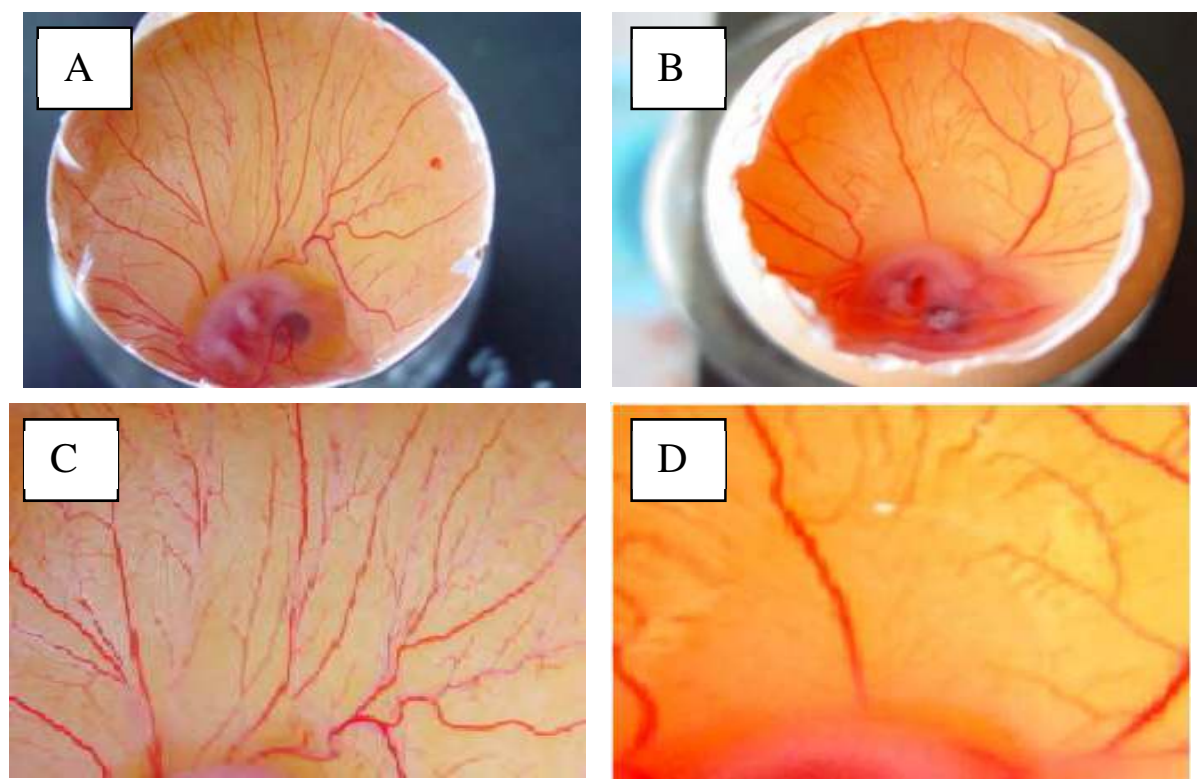

A and C: control with normal saline, B and D: albiziae treatment.

Fig. 2. Effect of Albizia julibrissin extracts on neovascularization in CAM (top, 10x; bottom, 20x).

\begin{tabular}{cccc}
\hline albiziae extract & \multicolumn{3}{c}{ No. of blood vessel } \\
\cline { 2 - 4 }$(\mu \mathrm{g} / \mathrm{mL})$ & Large & Medium & Small \\
$0($ control $)$ & $2.5 \pm 0.20$ & $3.5 \pm 0.67$ & $19.7 \pm 0.47$ \\
100 & $2.1 \pm 0.34$ & $3.9 \pm 0.53$ & $15.6 \pm 0.29$ \\
500 & $2.6 \pm 0.54$ & $2.8 \pm 0.97$ & $10.7 \pm 0.19^{*}$ \\
1000 & $2.5 \pm 0.67$ & $2.5 \pm 0.27$ & $6.8 \pm 0.48^{* *}$ \\
\hline
\end{tabular}

${ }^{*} P<0.05,{ }^{* *} P<0.01$ vs Control

Table 1. Effect of Albizia julibrissin extracts on neovascularization in CAM $(. x \pm s, n=10)$ 


\subsubsection{Albizia bark extracts inhibit vascularization in bFGF-induced Matrigel plugs}

Paraffin sections were obtained from implanted Matrigel plugs and stained for endothelial marker CD31 (Fig. 3A, as shown in brown). bFGF to induce substantial microvasculature formation in Matrigel plugs, as evidenced by the presence of abundant endothelial cells which were positively stained for CD31. Treatment with albizia extract decreased the amount of endothelial cells in bFGF-induced Matrigel plugs, suggesting an inhibition of microvasculature formation, while treatment with licorice extract had no discernable effect on angiogenesis. Plugs from uninduced Matrigel were rarely populated by endothelial cells.
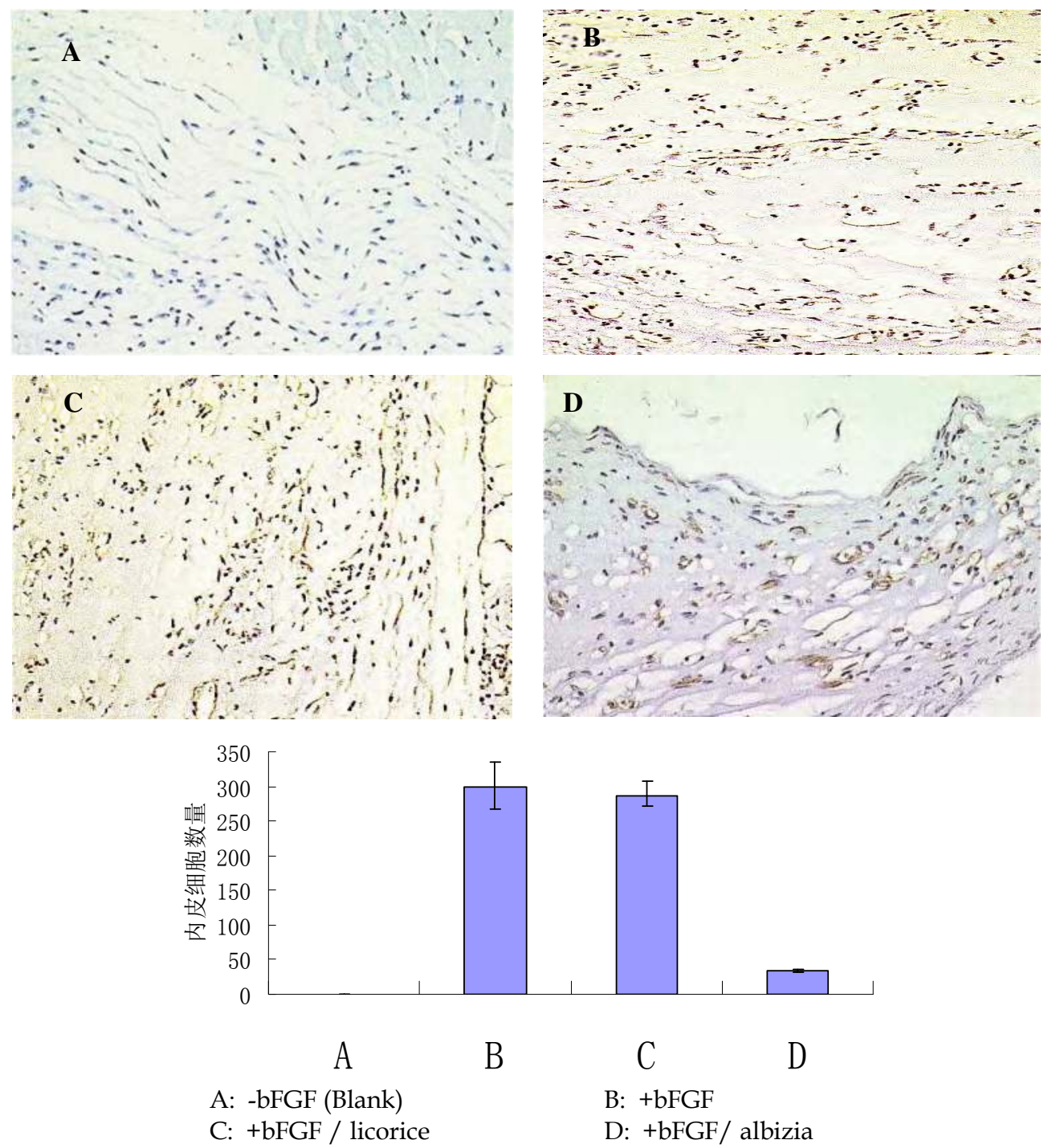

Fig. 3. Effect of Albizia julibrissin extracts on angiogenesis in matrigel plug (100x). 


\subsubsection{Albizia bark extracts inhibit neovascularization in C51 colon cancer mouse model}

Nude mice inoculated with C51 colon cancer cells developed tumor, which contained in blood vessels. Compared to control group that were administered with saline, albiziae treatment caused a $67.5 \%$ reduction in tumor growth, while licorice extract showed only a slight inhibition rate (IR)f $10 \%$ (Table 2). IHC of endothelial marker CD31 on tumor tissue sections revealed extensive vessel formation in control group (Fig. 4). Microvessel density (MVD) was measured with a light microscope in a single area of invasive tumor (200x field or $0.74 \mathrm{~mm}^{2}$ ) representative of the highest microvessel density (neovascular "hot spot"). This was done after endothelial cells, lining the microvessels, had been highlighted with antifactor VIII-related antigen/von Willebrand's factor (F8RA/vWF). Subsequent studies by other investigators, using either anti-F8RA/vWF or other relatively vessel-specific reagents such as anti-CD31. MVD was drastically reduced in albiziae-treated tumors, demonstrating that albiziae is a potent inhibitor of tumor neovascularization. Despite of its mild inhibition on tumor growth, licorice extract did not seem to have much effect on neovascularization, and there were no statistically significant differences between the control and licoricetreated groups.

The rate of inhibition (IR) $(\%)=\frac{(\text { negative control volume }- \text { test well volume) }}{(\text { negative control volume })} \times 100$

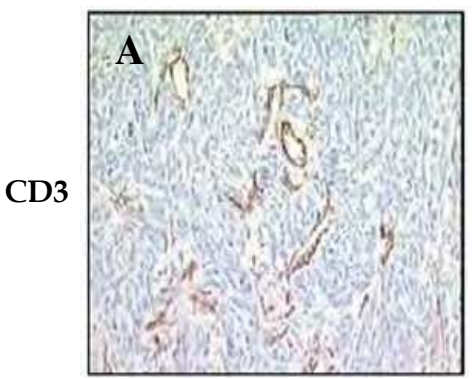

A: control

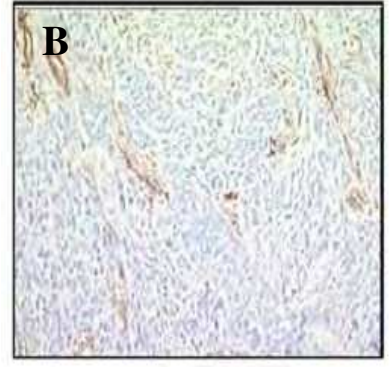

B: licorice extract

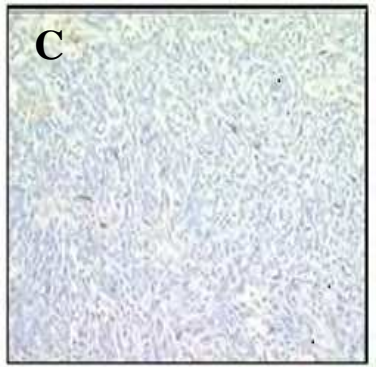

C: alzabiae extract

Fig. 4. Albizia julibrissin extracts reduced microvessel density in tumor.

\begin{tabular}{cccc}
\hline Group & No. of mice & IR $(\%)$ & MVD \\
Blank & 5 & 0 & $31.6 \pm 2.89$ \\
Licorice & 5 & 10 & $29.1 \pm 1.78$ \\
albiziae & 5 & 67.5 & $10.5 \pm 0.98$ * \\
\hline
\end{tabular}

${ }^{*} P<0.05$. vs Control

Table 2. The rate of inhibition (IR) of tumor growth and microvessel density (MVD) of different groups. 


\subsubsection{Albiziae extract inhibits metastasis in mouse LLC model}

Nude mice were inoculated with LLC cells and their lungs harvested and examined for the appearance of tumor as sign of metastasis. Five out of 10 mice in saline control group developed lung cancer with large nodules, the average size of tumor at $4.5 \pm 6.6 \mathrm{~mm}^{3}$; the tumor cells were variable in size, sometimes with giant cancer cells. The nodules appeared highly invasive and with abundant interstitial vessels (Fig. 5A). Normal lung tissues were compressed and damaged, and infiltrated by large number of inflammatory cells. The histopathology of tumor in licorice extract group showed no marked difference from saline group (Fig. 5B). Albiziae bark extracts, on the other hand, significantly improved and stabilized the cancer. Compared to the $50 \%$ metastasis rate in control group, only 1 in 8 mice from albiziae extracts group developed lung cancer, with an average size of $0.5 \pm 1.4 \mathrm{~mm}^{3}$. The nodule showed much reduced cell nuclear division and interstitial vasculature. No substantial infiltration by inflammatory cells was discovered. The combined results showed clear inhibition of LCC metastasis by albiziae extracts.

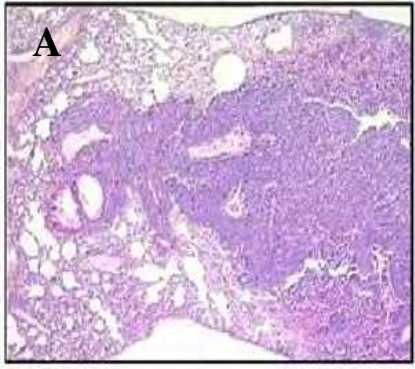

A: negative control

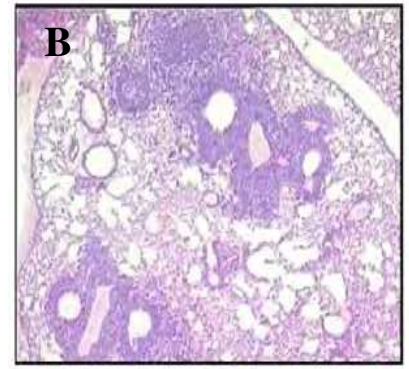

B: licorice extracts

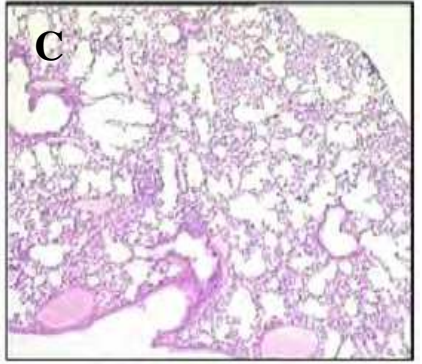

C: albizia extracts

Fig. 5. Antitumor effect of Albizia julibrissin extracts in mice implanted with LLC.

\subsection{The effect of albiziae effective monomer julibroside $J_{8}$ on neovascularization 3.2.1 Julibroside $J_{8}$ readily inhibits HMEC-1 cell proliferation}

In order to identify the specificity of anti-angiogenic of Julibroside $J_{8}$ in vitro, We first investigated the effect of Julibroside $J_{8}(1 \mu \mathrm{g} / \mathrm{ml}, 2 \mu \mathrm{g} / \mathrm{ml}, 5 \mu \mathrm{g} / \mathrm{ml}, 10 \mu \mathrm{g} / \mathrm{ml}, 20 \mu \mathrm{g} / \mathrm{ml})$ on proliferation of B16, MCF-7, hepG2, MRC-5 and HMEC-1. The results indicated that Julibroside $J_{8}$ caused a decrease in proliferation of B16, MCF-7, hepG2 and HMEC-1. The $\mathrm{IC}_{50}$ was estimated to be $10 \mu \mathrm{g} / \mathrm{ml}, 9.5 \mu \mathrm{g} / \mathrm{ml}, 8.8 \mu \mathrm{g} / \mathrm{ml}$ and $1.2 \mu \mathrm{g} / \mathrm{ml}$, respectively. But it did not significantly inhibit proliferation of normal cell (MRC-5) at the concentration of $20 \mu \mathrm{g} / \mathrm{ml}$. Another experiment in mice proved that julibroside $J_{8}$ had little effects on the quiescent vessels of kidney, lung, and liver.(Fig 6). The results show that $J_{8}$ has specific action on antiangiogenic in vitro and in vivo. 


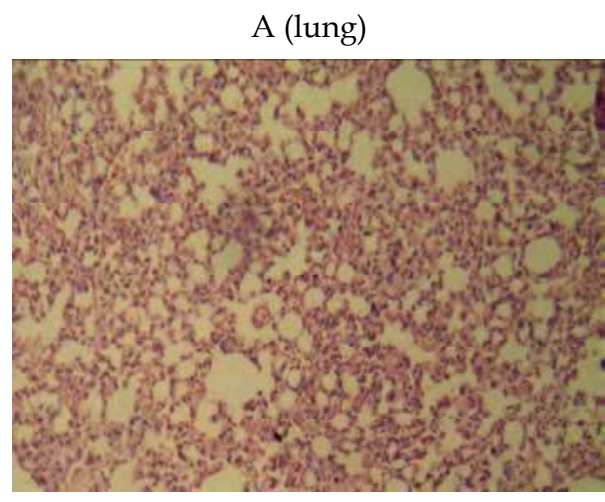

B (liver)

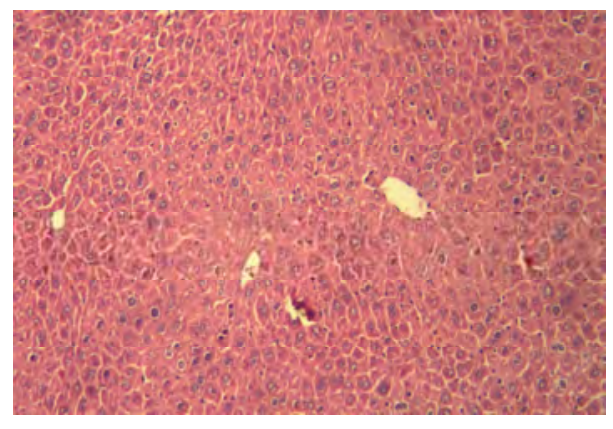

C (kidney)

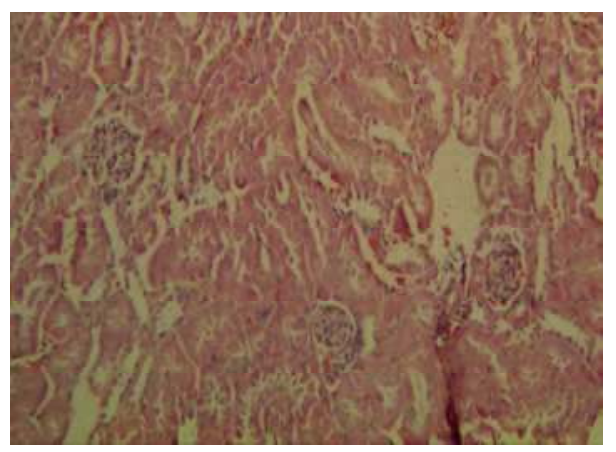

Fig. 6. No significant effect of julibroside $J_{8}$ on the quiescent vessels. 10x

\subsection{2 julibroside $J_{8}$ inhibits Matrigel tube formation in vitro}

As shown in Fig. 6, julibroside $J_{8}$ Demonstrated dose-dependent inhibition in Matrigel tube formation assay (Fig. 7). At $1 \mu \mathrm{g} / \mathrm{mL}$ of julibroside $J_{8}$, the number of tube formed was reduced. At $2.0 \mu \mathrm{g} / \mathrm{mL}$, HMEC-1 cells showed limited mobility and formed few tubes. At $4.0 \mu \mathrm{g} / \mathrm{mL}$, HMEC-1 cells had difficulty attaching. 


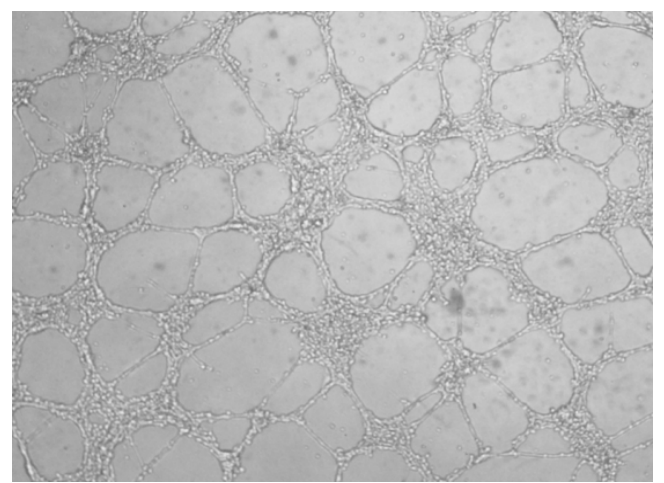

A (control)

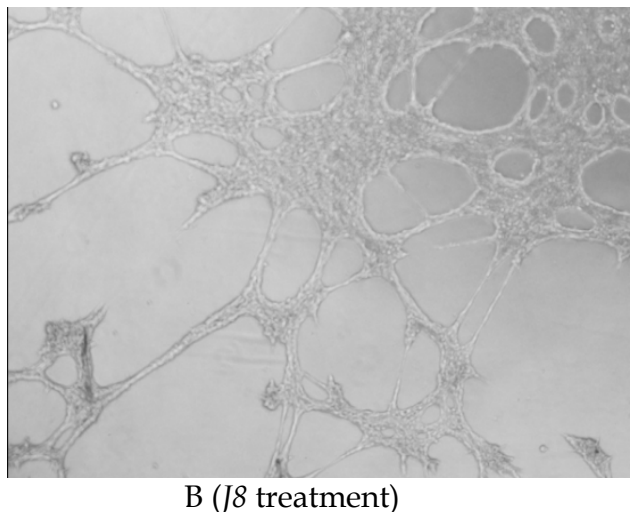

B (J8 treatment)

Fig. 7. Effect of julibroside $J_{8}$ on tube formation of HMEC-1.

\subsection{3 julibroside $J_{8}$ inhibits microvessel formation in CAM assay}

Compared to the microvessels formed in saline control group, the ones in julibroside $J_{8}$ treatment group were abnormal in appearance and sparsely distributed (Fig. 7) and the number of blood vessel in all three size categories (L, M, S) were reduced (Table 3) in a dosedependent manner, demonstrating a clear inhibition of neovascularization by julibroside $J_{8}$.

\begin{tabular}{cccc}
\hline julibroside $J_{8}(\mu \mathrm{g} / \mathrm{mL})$ & Narge & Medium & Small \\
\cline { 2 - 4 } 0 (control) & $2.8 \pm 0.20$ & $4.5 \pm 0.87$ & $21.8 \pm 1.89$ \\
10 & $2.1 \pm 0.34$ & $3.8 \pm 0.36$ & $16.6 \pm 0.65$ \\
50 & $2.6 \pm 0.54$ & $2.8 \pm 0.97$ & $9.9 \pm 0.30$ * \\
100 & $2.3 \pm 0.67$ & $2.5 \pm 0.27$ & $4.9 \pm 0.57$ ** \\
\hline
\end{tabular}

${ }^{*} P<0.05,{ }^{*} P<0.01$ vs Control

Table 3. Effect of julibroside $J_{8}$ on neovascularization in CAM $(. x \pm s, n=10)$.

\subsection{4 julibroside $J_{8}$ arrests cell cycle at G2/M phase}

FCM cell cycle analysis of HMEC-1 cells treated with julibroside $J_{8}$ at various concentrations for $48 \mathrm{hrs}$ showed a dose-dependent reduction of dividing cells (Table 4 and Fig. 8). At 0.5, 1.5 and $2.5 \mu \mathrm{g} / \mathrm{mL}$ of julibroside $\mathrm{J}_{8}$, the percentage of cells in S phase was decreased to $30.20 \%, 14.43 \%$ and $11.25 \%$, respectively, compared to $38.92 \%$ in the control group. In the mean time, increased number of cells was found in $\mathrm{G}_{2} / \mathrm{M}$ and sub G1 phases, while the number of cells in $G_{1}$ phase remained constant. 


\begin{tabular}{ccccc}
\hline \multirow{2}{*}{ Cell Cycle } & \multicolumn{4}{c}{ julibroside $J_{8}(\mu \mathrm{g} / \mathrm{mL})$} \\
\cline { 2 - 4 } & 0 & 0.5 & 1.5 & 2.5 \\
$\mathrm{~S}$ & $38.92 \%$ & $30.20 \%$ & $14.43 \%$ & $11.25 \%$ \\
$\mathrm{G}_{2} / \mathrm{M}$ & $8.66 \%$ & $21.35 \%$ & $29.15 \%$ & $30.25 \%$ \\
$\mathrm{G}_{1}$ & $52.42 \%$ & $48.43 \%$ & $56.47 \%$ & $54.2 \%$ \\
$\mathrm{Sub} \mathrm{G}_{1}$ & $0 \%$ & $7.11 \%$ & $15.85 \%$ & $16.49 \%$ \\
\hline
\end{tabular}

Table 4. Cell cycle analysis of HMEC-1 cells treated with julibroside J8.
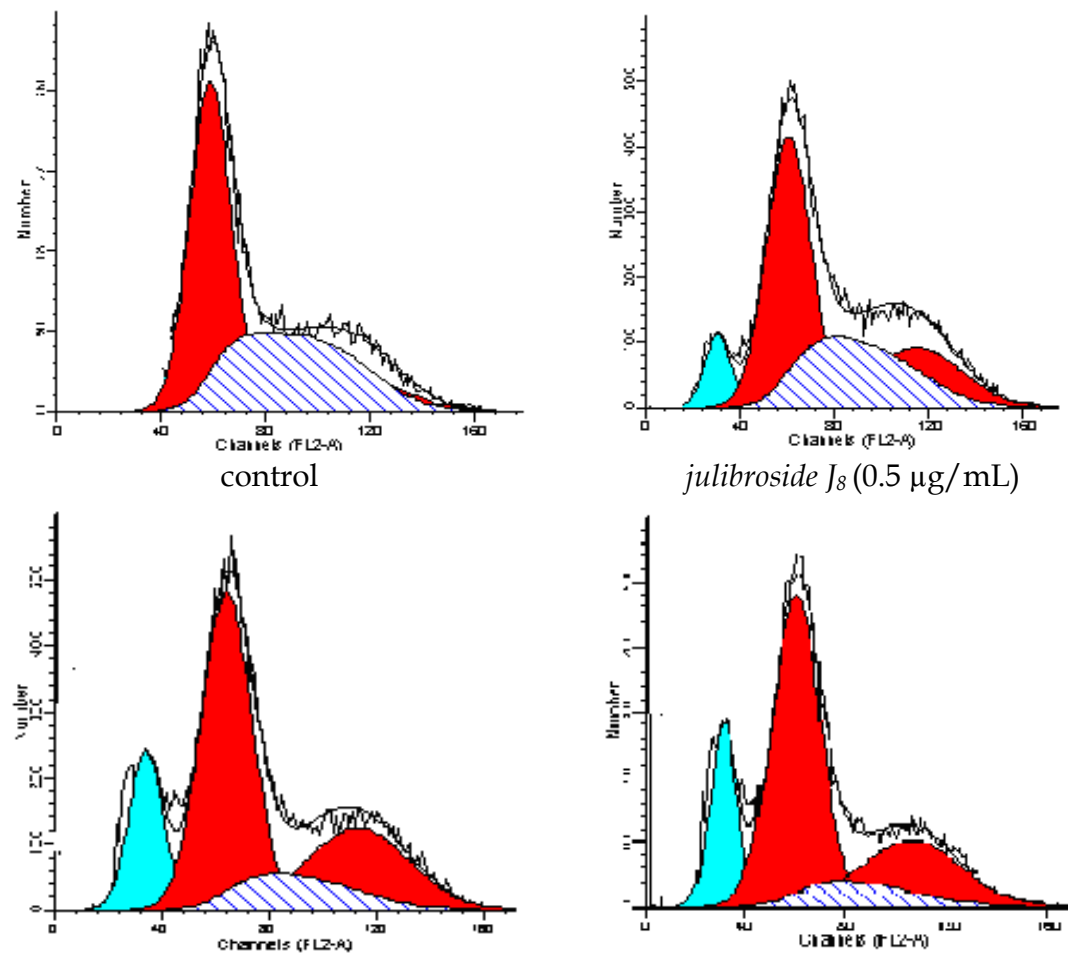

julibroside $J_{8}(0.5 \mu \mathrm{g} / \mathrm{mL})$

$$
\text { julibroside } J_{8}(1.5 \mu \mathrm{g} / \mathrm{mL})
$$

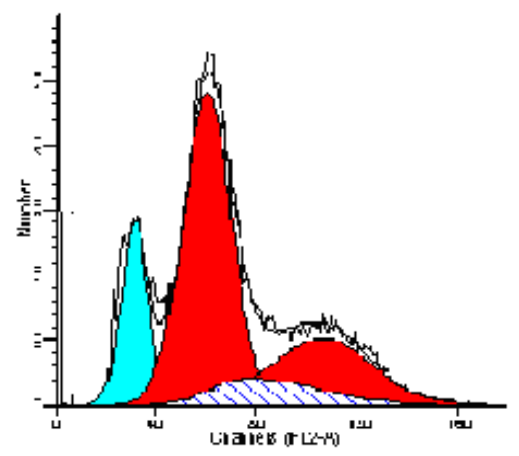

julibroside $J_{8}(2.5 \mu \mathrm{g} / \mathrm{mL})$

Fig. 8. Effects on cell cycle and apoptosis of HMEC-1 after treated with different concentration julibroside $J_{8}$.for $48 \mathrm{~h}$.

\subsection{Effect of julibroside $J_{8}$ on apoptosis and its mechanism}

\subsubsection{Observation of nuclear structure by DAPI staining}

HMCE-1 cells cultured on coverslips were stained with DAPI and their nuclear morphology was observed by fluorescent microscopy (Fig. 9). Control group in general showed weaker fluorescence, which was enhanced upon fixation. The nuclei appeared round, clear-edged, and uniformly stained. HMCE-1 cells treated with julibroside $J_{8}$ exhibited a stronger blue stain and displayed many characteristics associated with apoptotic cells, such as irregular 
edges around the nucleus, chromosome concentration in the nucleus, heavier coloring, and, with nuclear pyknosis, an increased number of nuclear body fragments.

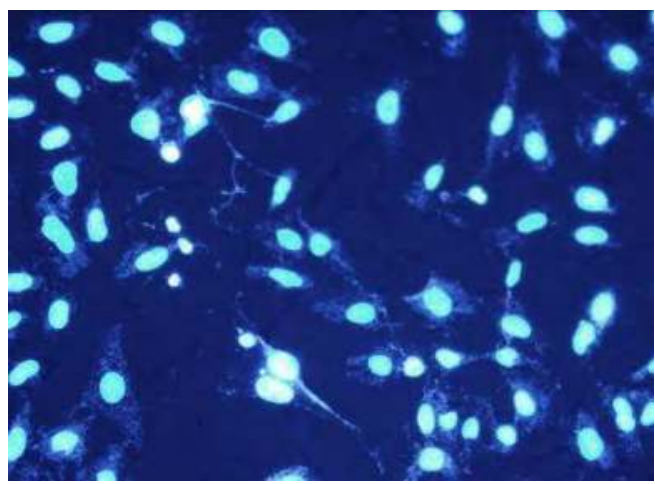

control $(\times 40)$

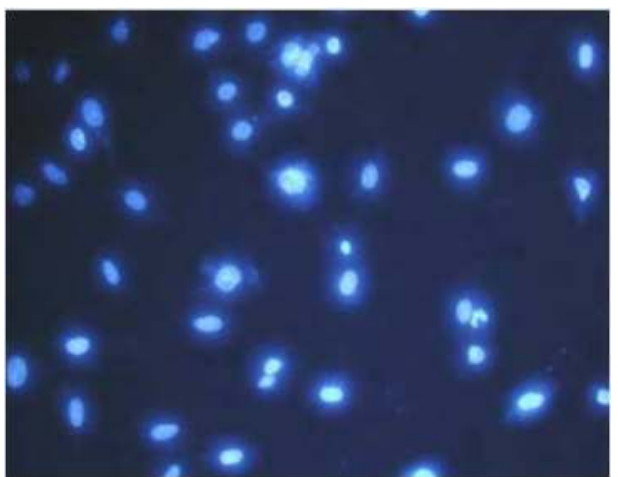

julibroside $J_{8}(2.0 \mathrm{ug} / \mathrm{ml})(\times 40)$

Fig. 9. The morphological change of HMEC-1 cells by DAPI.

\subsubsection{Determination of DNA fragmentation by TUNEL assay}

HMEC-1 cells grown on coverslips were stained for terminal deoxynucleotidyl transferase activity, an indication of DNA fragmentation and hallmark of late stage apoptosis. The reaction was developed with DAB chromogen and images examined by light microscopy (Fig. 10). Few nuclei were stained dark brown in untreated cells, whereas an increase of stained nuclei was detected in julibroside $J_{8}$-treated HMEC-1 cells in a dose-dependent manner, indicating julibroside $J_{8}$ is able to induce apoptosis.

\subsubsection{FCM analysis of Annexin V/ PI double labeling}

Annexin V/PI double staining coupled with FAM analysis allows the distinguishing of live cells (Annexin V neg, PI neg), early apoptotic cells (Annexin V pos, PI neg), and late apoptotic cells (Annexin $\mathrm{V}$ pos, PI pos). It was discovered that under treatment of increasing concentration of julibroside $J_{8}$ for $48 \mathrm{hr}$, increased cell number appeared in the two right quadrants of the histogram which was indicative of early and late apoptotic events. Compared to the combined apoptotic rate of $8.34 \%$ in the control group, julibroside $J_{8}$ treatment at $0.5,1.5$ and $2.5 \mu \mathrm{g} / \mathrm{mL}$ resulted in an significantly higher apoptotic rate of $13.63 \%, 19.55 \%$ and $32.32 \%$, respectively (Table 5).

\begin{tabular}{ccccc}
\hline \multirow{2}{*}{$\begin{array}{c}\text { Julibroside } J_{8} \\
(\mu \mathrm{g} / \mathrm{mL})\end{array}$} & $\begin{array}{c}\text { Live } \\
\text { cells }\end{array}$ & $\begin{array}{c}\text { Early apoptotic } \\
\text { cells }\end{array}$ & $\begin{array}{c}\text { Late apoptotic } \\
\text { cells }\end{array}$ & $\begin{array}{c}\text { Dead } \\
\text { cells }\end{array}$ \\
\hline 0 & 90.81 & 5.15 & 3.19 & 0.86 \\
0.5 & 82.91 & 8.14 & 7.79 & 1.16 \\
1.5 & 78.15 & 7.65 & 11.90 & 2.28 \\
2.5 & 67.96 & 8.94 & 21.38 & 1.72 \\
\hline
\end{tabular}

Table 5. Effects of julibroside $J_{8}$ on necrosis and apoptosis rate in HMEC-1 cells. 


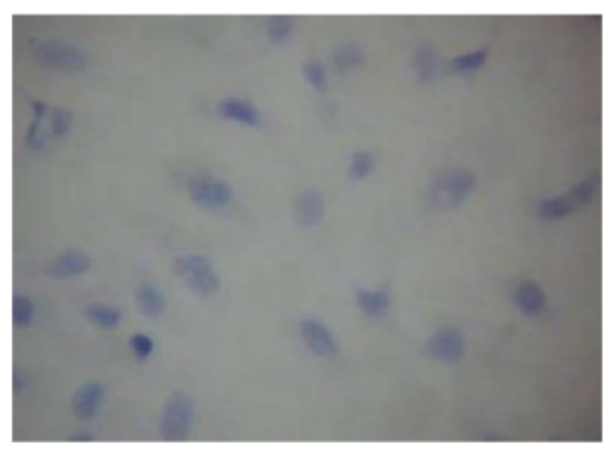

control

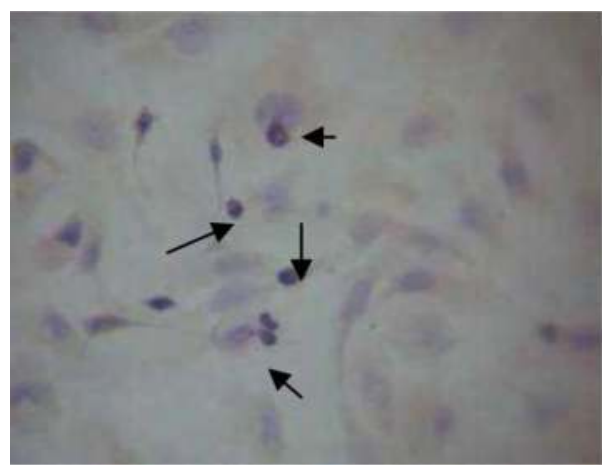

julibroside $J_{8}(1.5 \mu \mathrm{g} / \mathrm{mL})$

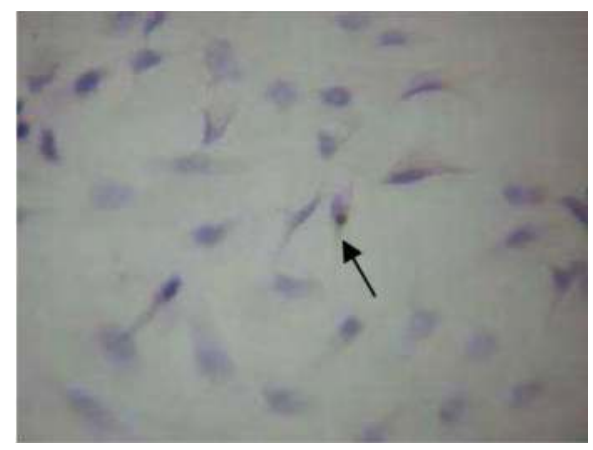

julibroside $J_{8}(0.5 \mu \mathrm{g} / \mathrm{mL})$

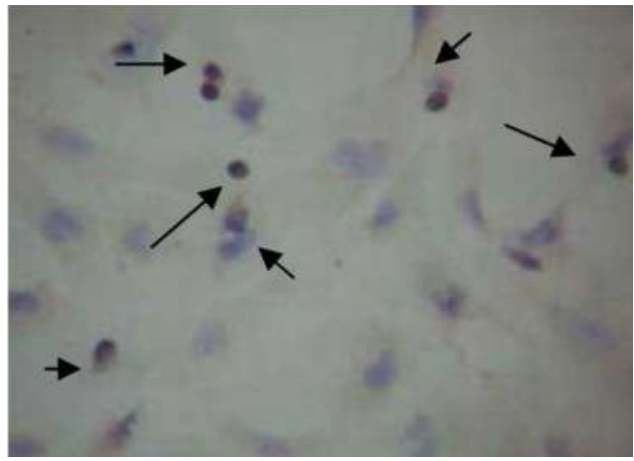

julibroside $J_{8}(2.5 \mu \mathrm{g} / \mathrm{mL})$

Fig. 10. Effect of julibroside $J_{8}$ on DNA fragmentation in HMEC-1 cells (400x).

\subsection{4 julibroside $J_{8}$ does not affect mitochondrial membrane potential $(\Delta \Psi \mathrm{m})$}

As shown in Fig. 12, treatment with increasing dose of julibroside $J_{8}$ did not result in change in HMEC-1 $\Delta \Psi \mathrm{m}$ accordingly, and there were no statistically significant differences between treated groups and control group, indicating that $\Delta \Psi \mathrm{m}$ is not involved in HMEC-1 cell apoptosis induced by julibroside $J_{8}$.

\subsubsection{Effect of julibroside $J_{8}$ on Caspase-3, 9 of HMEC-1}

As demonstrated in Table 6, treatment with julibroside $J_{8}$ did not change the activities of Caspase-3, 9, suggesting julibroside $J_{8}$-induced apoptosis is unrelated to Caspase-3, 9.

\begin{tabular}{lcccccc}
\hline & $\begin{array}{c}\text { lysis+reaction } \\
\text { buffer }\end{array}$ & blank & $\begin{array}{c}\text { negative } \\
\text { control }\end{array}$ & $4 \mathrm{~h}$ & $10 \mathrm{~h}$ & $24 \mathrm{~h}$ \\
\hline Caspase-3 & 0.053 & 0.063 & 0.231 & 0.258 & 0.234 & 0.214 \\
Caspase-9 & 0.053 & 0.060 & 0.219 & 0.229 & 0.203 & 0.199 \\
\hline
\end{tabular}

Table 6. The effect of julibroside $J_{8}(2 \mu \mathrm{g} / \mathrm{mL})$ on Caspase-3, 9 activities in HMEC-1 cell. 


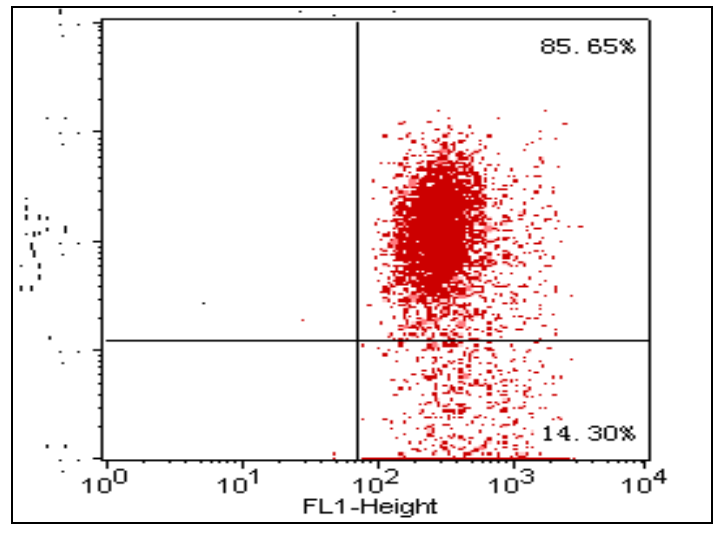

control

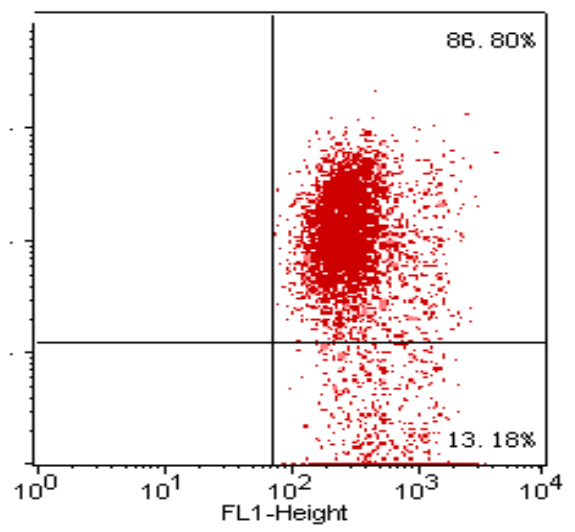

julibroside $J_{8}(0.5 \mu \mathrm{g} / \mathrm{mL})$

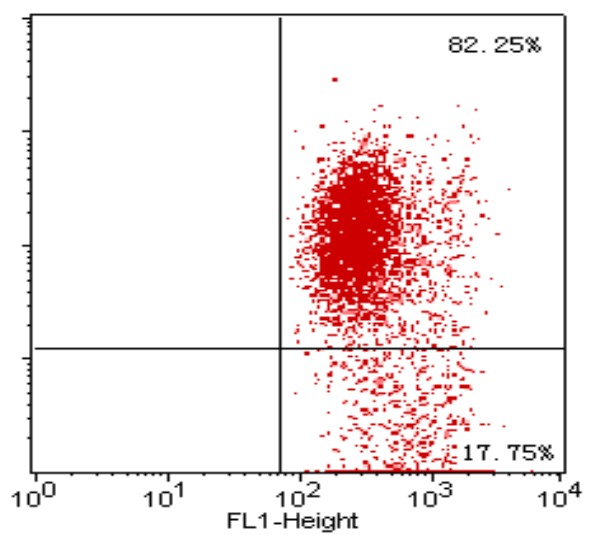

julibroside $\mathrm{J}_{8}(1.5 \mu \mathrm{g} / \mathrm{mL})$

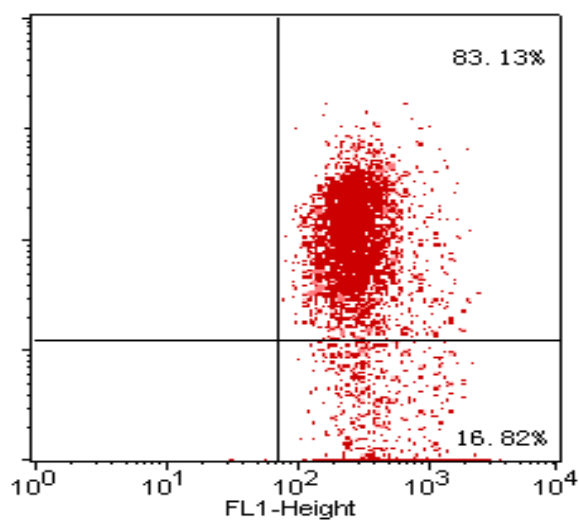

julibroside $J_{8}(1.0 \mu \mathrm{g} / \mathrm{mL})$

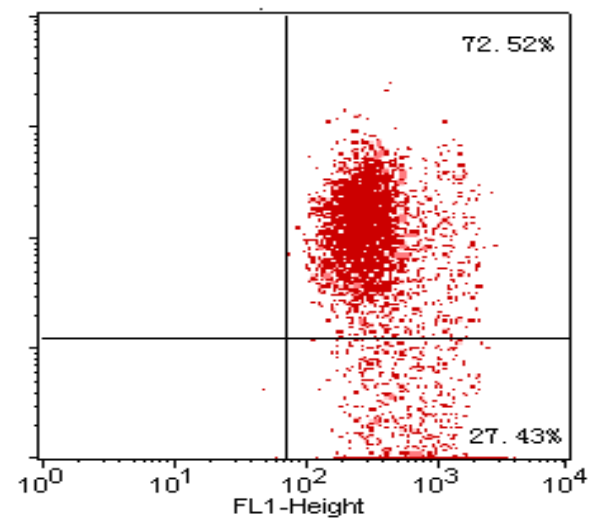

julibroside $J_{8}(2.5 \mu \mathrm{g} / \mathrm{mL})$

Fig. 11. Effect of julibroside $J_{8}$ on $\Delta \Psi \mathrm{m}$ in HMEC-1 cells after incubation for $24 \mathrm{~h}$. 


\section{Discussion}

Invasiveness, metastasis and hyperproliferation are the key issues in tumor cell biology. Since Folkman proposed the concept of angiogeneis in 1972, tumor neovascularization has attracted much interest from the field of biological medicine and pharmaceutical industry, and been applied to the research and development of novel anticancer drugs, namely angiogenesis inhibitors targeting vessel endothelial cells to block the blood and nutrient supply to tumor and thus its growth and metastasis[5-6]. Using HMEC-1 cell proliferation inhibition assay as HTS read-out, our study identified 4, out of 500, medicinal herbs that function as neovascularization inhibitors, and among which albizia bark extract was shown to be able to inhibit tumor neovascularization and metastasis by in vitro and in vivo assays.

Monitored by HMEC-1 proliferation inhibition assay, we obtained effective monomer julibroside $J_{8}$ through a series of separation and purification steps. In vitro cell-based assay determined the $\mathrm{IC}_{50}$ of julibroside $\mathrm{J}_{8}$ on HMEC-1 proliferation as $1.2 \mu \mathrm{g} / \mathrm{mL}$. Julibroside $\mathrm{J}_{8}$ can also inhibit Matrigel tube formation in vitro and neovascularization in CAM assay.

Our results showed that julibroside $J_{8}$ treatment changed cell cycle distribution, resulting in more cells at $\mathrm{G}_{2} / \mathrm{M}$ phase and less at $S$ phase, and the appearance of sub- $\mathrm{G}_{1}$ peak of apoptosis, which demonstrate that julibroside $J_{8}$ is capable of cell proliferation inhibition and induction of apoptosis. Similarly, apoptosis was detected by Annexin V-FITC/PI double labeling.

Apoptosis is a cellular response to certain environmental messages and thus regulated by various endogenous and exogenous factors. Mitochondria are a vital cell organelle whose main function is energy conversion. In addition, mitochondria are involved in a range of other processes, such as signaling, cellular differentiation, cell death, as well as the control of the cell cycle and cell growth. A large body of work has established the involvement of mitochondria in apoptosis, and alterations in $\Delta \Psi \mathrm{m}$ has been regarded as one of the earliest events in cell death, prior to the appearance of such hallmarks as chromatin condensation and DNA fragmentation. Once $\Delta \Psi \mathrm{m}$ collapses, apoptosis becomes irreversible. Our study showed that julibroside $J_{8}$ treatment leads to the decrease in HMEC-1 cell number. DAPI stain illustrated cell shrinkage, membrane blebbing and increasing cellular debris when cells were treated with high concentration of julibroside $J_{8}$. In addition, DNA fragmentation was identified by TUNEL Apoptosis assay. FCM analysis revealed that cells were arrested at $\mathrm{G}_{2} / \mathrm{M}$ phase of the cell cycle following julibroside $J_{8}$, accompanied by a sizable peak of apoptosis. Further analysis by Annexin-V/PI double labeling proved the dose-dependent effect of julibroside $J_{8}$ on apoptosis. However, $\Delta \Psi \mathrm{m}$ did not seem to be affected.

Members of caspase family play a vital role in mitochondria-mediated apoptosis; the key players among them are caspase-3 and 9. Both are present in cytosol under normal physiological conditions as inactive precursors. When cellular stress (eg. DNA damage) occurs, procaspase- 9 is activated by cytochrome c released from mitochondria; the resulting caspase- 9 in turn activates the downstream procaspase-3. The activated caspase-3, a key factor in apoptosis execution, cleaves a host of downstream substrate and cell undergoes apoptosis. However, our study did not detect the change in caspase-3/9 acitivity as a function of time, suggesting julibroside $J_{8}$ induces apoptosis in HMCE-1 cells in mechanism independent of mitochondria pathway.

In all, we conclude that julibroside $J_{8}$, a novel molecule purified from albizia bark extracts, is able to inhibit HMEC- 1 cell proliferation by cell cycle arrest at $\mathrm{G}_{2} / \mathrm{M}$ phase. In addition, we proved by multiple means that julibroside $J_{8}$ can induce apoptosis. However, julibroside $J_{8}$ does not seem to affect $\Delta \Psi_{\mathrm{M}}$ nor caspase-3/9 activity, suggesting a mitochondriaindependent apoptosis pathway. 


\section{References}

[1] Akhtar, N., Dickerson, E.B., Auerbach, R. The sponge/matrigel angiogenesis assay. Angiogenesis 2002, 5, 75-80.

[2] Ley, C.D., Olsen, M.W.B., Lund, E.L., et al. Angiogenic synergy of bFGF and VEGF is antagonized by angiopoietin-2 in a modified in vivo matrigel assay. Microvascular Research2004, 68, 161-168.

[3] Valster, A., Tran, N.L., Nakada, M., et al. Cell migration and invasionassays. Methods $2005,37,208-215$.

[4] Soeda, S., Kozako, T., Iwata, K., et al. Oversulfated fucoidan inhibits the basic fibroblast growth factor-induced tube formation by human umbilical vein endothelial cells: its possible mechanism of action. Biochim.Biophys. Acta 2000,1497, 127-134.

[5] Kowanetz M, Ferrara N: Vascular endothelial growth factor signaling pathways: therapeutic perspective. Clin Cancer Res 2006, 12:5018-5022.

[6] Goodwin AM. In vitro assays of angiogenesis for assessment of angiogenic and antiangiogenic agents. Microvasc Res 2007, 74:172-183 


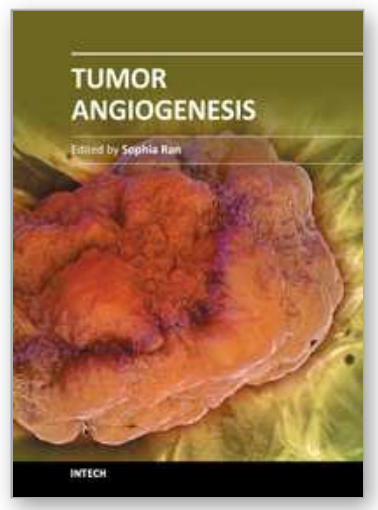

\author{
Tumor Angiogenesis \\ Edited by Dr. Sophia Ran
}

ISBN 978-953-51-0009-6

Hard cover, 296 pages

Publisher InTech

Published online 17, February, 2012

Published in print edition February, 2012

Tumor angiogenesis is the main process responsible for the formation of new blood vessels that promote tumor growth and metastasis. This process is driven by potent pro-angiogenic factors that are predominant in the tumor environment and are produced by both malignant cells and the host cells recruited to the tumor site. Tumor environment is characterized by the imbalance between pro-angiogenic and anti-angiogenic factors, which drives the construction of numerous but structurally defective vessels. These poorly perfused and abnormal vessels significantly contribute to the tumor pathology not only by supporting the expansion of the tumor mass but also by promoting chronic inflammation, enhancing thrombosis, impeding drug delivery, and disseminating tumor cells. These problems associated with tumor vasculature continue to attract great attention of scientists and clinicians interested in advancing the understanding of tumor biology and development of new drugs. This book complies a series of reviews that cover a broad spectrum of current topics related to the pathology of tumor blood vessels including mechanisms inducing new vessels, identification of new targets for inhibition of tumor angiogenesis, and potential clinical use of known and novel anti-angiogenic therapies. The book provides an update on tumor angiogenesis that could be useful for oncologists, cancer researchers and biologists with interests in vascular and endothelial cell behavior in the context of cancer.

\title{
How to reference
}

In order to correctly reference this scholarly work, feel free to copy and paste the following:

Jian Jin, Li-Ying Qiu, Hui Hua and Lei Feng (2012). The Effect of Chinese Herb on Tumor Angiogenesis by Inhibiting Vessel Endothelial Cells, Tumor Angiogenesis, Dr. Sophia Ran (Ed.), ISBN: 978-953-51-0009-6, InTech, Available from: http://www.intechopen.com/books/tumor-angiogenesis/the-effects-of-chinese-herbson-tumor-angiogenesis-by-inhibiting-vessel-endothelial-cells

\section{INTECH}

open science | open minds

\section{InTech Europe}

University Campus STeP Ri

Slavka Krautzeka 83/A

51000 Rijeka, Croatia

Phone: +385 (51) 770447

Fax: +385 (51) 686166

\section{InTech China}

Unit 405, Office Block, Hotel Equatorial Shanghai

No.65, Yan An Road (West), Shanghai, 200040, China 中国上海市延安西路65号上海国际贵都大饭店办公楼 405 单元

Phone: +86-21-62489820

Fax: +86-21-62489821 
www.intechopen.com 
(C) 2012 The Author(s). Licensee IntechOpen. This is an open access article distributed under the terms of the Creative Commons Attribution 3.0 License, which permits unrestricted use, distribution, and reproduction in any medium, provided the original work is properly cited. 